\title{
A Review of Existing Therapies for Actinic Keratosis: Current Status and Future Directions
}

\author{
Laura Del Regno ${ }^{1}$ - Silvia Catapano ${ }^{2} \cdot$ Alessandro Di Stefani $^{1,2} \cdot$ Simone Cappilli $^{2} \cdot$ Ketty Peris $^{1,2}$
}

Accepted: 24 January 2022 / Published online: 19 February 2022

(c) The Author(s) 2022, corrected publication [2022]

\begin{abstract}
Actinic keratosis (AK) is a chronic skin disease in which clinical and subclinical cutaneous lesions coexist on sun-exposed areas such as the head and neck region and the extremities. The high prevalence of AK means the disease burden is substantial, especially in middle-aged and elderly populations. Evidence indicates that AK may progress into invasive cutaneous squamous cell carcinoma, so the European guidelines recommend treatment of any AK regardless of clinical severity. Given the aging population and therefore the increasing incidence of AK and cutaneous field carcinogenesis, further updates on the long-term efficacy of current therapies and new investigational agents are critical to guide treatment choice. Patients often have difficulty adequately applying topical treatments and coping with adverse local skin reactions, leading to less than optimum treatment adherence. The development of associated local skin symptoms and cosmetic outcomes for the area of interest are also relevant to the choice of an appropriate therapeutic strategy. Treatment is always individually tailored according to the characteristics of both patients and lesions. This review focuses on the therapeutic approaches to AK and illustrates the currently available home-based and physician-managed treatments.
\end{abstract}

\section{Key Points}

This article illustrates the scientific evidence driving the clinical management of patients affected by actinic keratosis, aiming to provide a patient-tailored treatment program.

Phase II/III clinical trials are showing promising results from new topical agents.

The goals of actinic keratosis treatment are to eradicate as many clinical and subclinical lesions as possible, achieve as prolonged a clinical remission as possible, provide a good cosmetic result, and prevent progression to invasive squamous cell carcinoma.

Laura Del Regno

delregnolaura@gmail.com

1 Dermatologia, Dipartimento di Scienze Mediche e Chirurgiche, Institute of Dermatology, Fondazione Policlinico Universitario A. Gemelli IRCCS, Largo A. Gemelli 8, 00168 Rome, Italy

2 Dermatologia, Dipartimento Universitario di Medicina e Chirurgia Traslazionale, Università Cattolica del Sacro Cuore, Rome, Italy

\section{Introduction}

Actinic keratosis (AK) is an intraepithelial keratinocyte neoplasm that typically occurs on sun-exposed areas in adults [1-5]. The main constitutional and exposure risk factors include chronic exposure to ultraviolet radiation, use of sunbeds, advanced age (up to $80 \%$ of adults aged $>60$ years are affected), male sex, Fitzpatrick skin type I-II, prolonged immunosuppression, and previous history of AK and non-melanoma skin cancer [6]. Regular use of sunscreen, body mass index $\geq 25.0 \mathrm{~kg} / \mathrm{m}^{2}$, and a low educational level represent protective factors [7]. The prevalence of AK varies widely across continents, with the highest rates reported in Australia, where 40-60\% of white individuals aged $\geq 40$ years have at least one AK [8]. In Europe, the prevalence rates vary from $4.7 \%$ (in a cross-sectional French study [9]) to $31 \%$ (in Austrian individuals aged $\geq 30$ years and screened by office-based dermatologists [10]) and up to $37 \%$ in the more recent Rotterdam Study, which included a population-based cohort of 2061 elderly individuals [11]. In a recent Italian study, our group reported the development of $\mathrm{AK}$ in $27.4 \%$ of patients attending general dermatology outpatient clinics [7]. More than half of patients had one to five $\mathrm{AK}$, and over three-quarters had face or neck lesions. The high prevalence of AK in Italy is in line with the overall rate of $28.4 \%$ detected in a Spanish dermatology outpatient 
population aged $\geq 45$ years [12]. Although data about the prevalence of AK are not easily comparable because of differences in methodologies (e.g., office-based vs. populationbased cohorts vs. cross-sectional studies, patient age groups, etc.), the prevalence is higher in men than in women, with an age-related linear increase. Therefore, the economic burden of AK is expected to rise substantially over the next decades with the increasingly ageing global population with chronic lifetime sun exposure [11, 13, 14].

Clinical grading by Olsen et al. [15] classifies AK lesions as grade 1 (flat pink macules; hardly visible lesions; easy to feel and difficult to see), grade 2 (moderately thick, red, scaly lesions; easily felt and seen), and grade 3 (very thick, hyperkeratotic lesions that can be difficult to differentiate from early squamous cell carcinomas [SCCs]). This classification, which is commonly used in clinical practice, has several limitations, and recent studies demonstrated that the clinical Olsen et al. grading does not accurately match with the histological classification, with the Olsen grading being lower than the assumed histological grade in $62.4 \%$ of cases [16]. In addition, Fernández-Figueras and colleagues [17, 18] showed that AK, including in its early phase, may progress into invasive cutaneous SCC (so-called "differentiated pathway") without following progressive stages of keratinocyte intraepidermal neoplasia ("classical pathway"). These findings have introduced the paradigm that all single AK lesions as well as the field cancer (FC) should be treated, since the surrounding area may harbor subclinical alterations supported by genetic changes, similar to AK. Additional studies also highlighted that the hair follicle may contribute significantly to the development of deeply invasive cutaneous SCC, correlating with the follicular extension of atypical keratinocytes in AK [19]. These data have important implications for the clinical management of AK, as supported by a European multicenter consensus recommending that both single lesions and FC be treated, taking into consideration the patient's needs and profile [20].

\section{Methods}

We completed a literature review searching the PubMed, Embase, and Cochrane library CENTRAL electronic databases until 1 September 2021 for all relevant records. Search terms included actinic keratosis or relevant treatment modalities (e.g., photodynamic therapy [PDT], 5-fluorouracil (5-FU), imiquimod, diclofenac, cryosurgery, surgical excision, laser therapy). Studies were included in this review if they reported randomized controlled trials in humans comparing different treatments for $\mathrm{AK}$ or investigating different dosages of active treatments. Clinical guidelines, interventional studies, expert consensus, and case series focusing on the management of $\mathrm{AK}$ were also considered.
Case reports and papers not written in the English language were excluded.

\section{Clinical Features and Diagnosis}

The prototypical clinical features of AKs are erythematous scaling patches or plaques located on sun-exposed areas such as the face, scalp, or upper extremities in middle-aged and elderly males. The presence of AK is considered a clinical mark of skin photoaging; they often present as multiple lesions and less frequently as single or a few, either circumscribed or scattered. AK lesions are usually asymptomatic but may occasionally be pruritic or stinging (Fig. 1). The presence of numerous and/or recurrent AK lesions on sunexposed skin is known as "field cancerization or field cancer", which is defined as an area surrounding the visible AK that may phenotypically appear as normal skin but instead harbors genetic changes similar to those observed in AK [21]. In the context of AK, the FC may be independently initiated by many cells following a mutagenic insult caused by ultraviolet radiation within p53, promoting a clonal expansion of cells and formation of a contiguous patch of cancerprimed cells [22].

The different histomorphologic variants include atrophic, hypertrophic, acantholytic, pigmented, lichenoid, and Bowenoid AK [21].

The diagnosis of AK is mainly based on clinical appearance, although imaging techniques are useful noninvasive diagnostic tools. Among these, dermatoscopy can be used to differentiate AK from invasive cutaneous SCC and to diagnose lesions at an early stage. In addition, reflectance confocal microscopy and high-definition optical coherence tomography may allow the detection of clinically invisible subclinical lesions and monitoring of treatment efficacy [23]. Biopsy of an AK lesion is recommended in equivocal cases in which differential diagnosis-including basal cell carcinoma, Bowen's disease, invasive cutaneous SCC, amelanotic melanoma, lentigo maligna melanoma, and superficial seborrheic keratosis-cannot be ruled out with clinical examination and imaging techniques [24].

\section{Management of Actinic Keratosis (AK)}

Several treatments, with different efficacy and safety profiles, are currently available for the management of AK [20]. Therapies are classified as "lesion directed" (i.e., treatments are performed on a single or very few AK lesions within the same area) or "field directed," which target the FC, i.e., the clinically visible lesions and the whole surrounding area with subclinical changes [25, 26]. Table 1 summarizes the 
Fig. 1 a Single actinic keratosis visible as a scaly erythematous lesion on the cheek of an elderly patient; b representative illustration of field cancerization of the scalp of an elderly patient

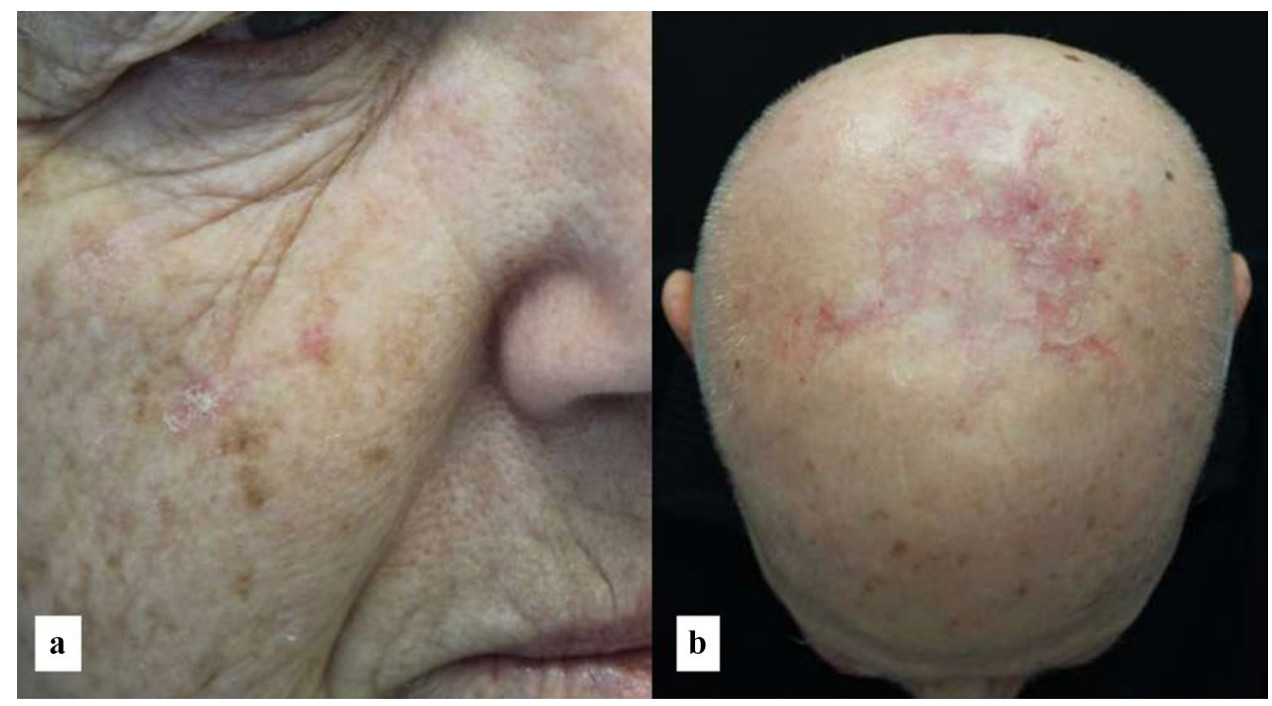

main treatments and their therapeutic indications, protocols, and response rates.

The treatment choice is typically individually tailored and always based on the characteristics of both patients and lesions, particularly in elderly patients. This group of patients with AK very often also have comorbidities such as hypertension, cardiovascular disease, diabetes, and neurological dysfunctions that need to be considered when choosing a specific treatment and to predict the patient's ability to adhere to treatment [46]. In other instances, treatments for AK can also be quite distressing for many patients because of the impact on daily activities such as work and social engagements, especially for lesions located in visible parts of the body such as the face and scalp [47, 48]. The patient's ability to perform a home-based treatment is a significant issue to consider, along with the need for a caregiver to correctly apply the therapy. It would be appropriate in some circumstances to involve the patient in the treatment-decision process and to provide an educational program to prevent or reduce the severity of local skin reactions.

\section{Home-Based Treatments}

Home-based topical AK treatments include imiquimod, 5-FU, diclofenac, and tirbanibulin. They have different mechanisms of action, dosages, and treatment durations, and their use requires adequate education both to ensure therapeutic adherence and for the management of any adverse events.

\subsection{Imiquimod}

Imiquimod is a toll-like receptor (TLR)-7 agonist that acts as a topical immune-response modifier. TLRs, located on the surface of dendritic cells, monocytes, macrophages, and Langerhans cells, promote the activation of the innate and adaptive immune response, leading to the release of cytokines and chemokines. In addition, imiquimod induces a direct apoptotic effect on tumor cells [49]. Imiquimod is approved at $5 \%, 3.75 \%$, and $2.5 \%$ concentrations for $\mathrm{AK}$ located on the face or scalp in immunocompetent adult patients. The $5 \%$ formulation is used to treat small clusters of AK lesions in an area $\leq 25 \mathrm{~cm}^{2}$ on the face and scalp, with a schedule of three times a week for a 4-week course followed by an additional cycle if clearance is partial [27, 28] (Fig. 2). Both the $3.75 \%$ and the $2.5 \%$ formulation creams are applied once daily for a 2 -week cycle, followed by 2 weeks off and another 2 -week cycle of treatment, oralternatively-once daily for two 3-week periods separated by 3 weeks off treatment [29-31]. The $3.75 \%$ and $2.5 \%$ formulations have shown significant clinical advantages over $5 \%$ imiquimod, since a similar efficacy is achieved with a lesser degree of adverse events and a shorter treatment duration; moreover, lower formulations allow the inclusion of a wider area (entire face or balding scalp) [50, 51].

The most reported side effects with imiquimod include itching, burning pain, and soreness at the application site, with other localized reactions including erythema, scabbing and crusting, erosions, and vesiculation [24]. Flu-like symptoms may also arise and increase in a dose-dependent manner [29]. High rates of skin reactions, prolonged discomfort, and the continued need for procedural treatments may make patients less willing to use imiquimod or topical 5-FU for AK [52]. Because of the very common local skin reactions due to its mechanism of action, treatment with imiquimod is not recommended during summer and is not the first choice in immunosuppressed patients. In addition, patients who start imiquimod should be informed that the drug should be applied a few centimeters away from the eyes, avoiding 
Table 1 Treatments currently available for the management of actinic keratosis

\begin{tabular}{|c|c|c|c|}
\hline Active treatment & AK location/size of treatment area & Treatment regimen/procedure & Efficacy (complete clearance) ${ }^{\mathrm{a}}$ \\
\hline \multicolumn{4}{|l|}{ Home-based treatment } \\
\hline \multicolumn{4}{|l|}{$\mathrm{IMQ}^{\mathrm{b}}$} \\
\hline $5 \%$ IMQ cream & Face or balding scalp/area $\leq 25 \mathrm{~cm}^{2}$ & $\begin{array}{l}\text { Two 4-week courses (TIW) sepa- } \\
\text { rated by } 3 \text { weeks off treatment }\end{array}$ & $53.7-55 \%[27,28]$ \\
\hline $3.75 \%$ IMQ cream & Face or balding scalp/area $\geq 25 \mathrm{~cm}^{2}$ & $\begin{array}{l}\text { Two 3-week courses separated by } 3 \\
\text { weeks off treatment; two } 2 \text {-week } \\
\text { cycles separated by a } 2 \text {-week rest } \\
\text { period }\end{array}$ & $34 \%$ [29]; 35.6\% [30] \\
\hline $2.5 \%$ IMQ cream & Face or balding scalp/area $\geq 25 \mathrm{~cm}^{2}$ & $\begin{array}{l}\text { Two 2-week periods separated by } \\
2 \text { weeks off; two } 3 \text {-week periods } \\
\text { separated by } 3 \text { weeks off }\end{array}$ & $33.3 \%[30] ; 43.2 \%[31]$ \\
\hline \multicolumn{4}{|l|}{$5-\mathrm{FU}^{\mathrm{b}}$} \\
\hline $5 \% 5$-FU cream or solution & Face or scalp & Twice daily for 4 weeks & $42.9-76.6 \%[32]$ \\
\hline $4 \% 5$-FU cream & Face or scalp & Once daily for 4 weeks & $80 \%[33]$ \\
\hline $0.5 \% 5$-FU cream & Face or scalp & Once or twice daily $\leq 4$ weeks & $47.5-57.8 \%[34,35]$ \\
\hline $\begin{array}{l}0.5 \% 5 \text {-FU solution with } 10 \% \\
\text { SA }\end{array}$ & Face, scalp/area $\leq 25 \mathrm{~cm}^{2}$ & Once daily for 12 weeks & $49.5 \%[36]$ \\
\hline 3\% Diclofenac gel ${ }^{\mathrm{b}}$ & Face or scalp/area $\leq 25 \mathrm{~cm}^{2}$ & Twice daily for $60-90$ days & $41 \%[37]$ \\
\hline $0.8 \%$ Piroxicam cream $^{\mathrm{b}}$ & $\begin{array}{l}\text { Face, scalp, trunk, and extremities/ } \\
\text { area } \leq 35 \mathrm{~cm}^{2}\end{array}$ & Twice daily for 6 months & $55 \%[38]$ \\
\hline $1 \%$ Tirbanibulin ointment $\mathrm{t}^{\mathrm{b}}$ & Face or scalp/area $\leq 25 \mathrm{~cm}^{2}$ & Once daily for 5 days & $49 \%[39]$ \\
\hline \multicolumn{4}{|l|}{ Physician-managed treatments } \\
\hline Cryotherapy $^{\mathrm{c}}$ & $\begin{array}{l}\text { Face, scalp, trunk, and extremities/ } \\
\text { single lesion }\end{array}$ & $\begin{array}{l}\text { One to three freeze-thaw cycles } \\
\text { with various durations of the } \\
\text { procedure }\end{array}$ & $39-76 \%[40]$ \\
\hline \multicolumn{4}{|l|}{$\mathrm{PDT}^{\mathrm{b}}$} \\
\hline $\begin{array}{l}\text { Conventional PDT: } 16 \% \text { MAL, } \\
8 \% \text { ALA }\end{array}$ & Face, scalp, forearms & $\begin{array}{l}\text { Incubation time with photosensitiz- } \\
\text { ing cream about } 3 \text { h; irradiation } \\
\text { time, a few minutes (420-1000 } \\
\text { seconds). Single treatment ses- } \\
\text { sion; treated lesions should be } \\
\text { evaluated after } 3 \text { months and, if } \\
\text { necessary, a second treatment } \\
\text { session given }\end{array}$ & $\begin{array}{l}69-93 \% \text { (face and scalp); } \\
44-80 \% \text { (forearms) [41] }\end{array}$ \\
\hline Patch 5-ALA ( $\left.2 \mathrm{mg} / \mathrm{cm}^{2}\right)$ & Face, bald scalp $/ \leq 1.8 \mathrm{~cm}$ diameter & $\begin{array}{l}\text { Incubation time with photosensitiz- } \\
\text { ing cream about } 4 \text { h; irradiation } \\
\text { time, a few minutes (420-1000 } \\
\text { seconds). Single treatment ses- } \\
\text { sion; treated lesions should be } \\
\text { evaluated after } 3 \text { months and, if } \\
\text { necessary, a second treatment } \\
\text { session given }\end{array}$ & $47-87 \%[42]$ \\
\hline Daylight PDT, $16 \%$ MAL & Face, scalp & $\begin{array}{l}\text { Incubation time with photosensi- } \\
\text { tizing cream about } 30 \text { minutes; } \\
\text { irradiation time about } 2 \mathrm{~h} \text {. Single } \\
\text { treatment session: treated lesions } \\
\text { should be evaluated after } 3 \\
\text { months and, if necessary, a second } \\
\text { treatment session given }\end{array}$ & $70-89 \%[43,44]$ \\
\hline \multicolumn{4}{|l|}{ Chemical peelings ${ }^{\mathrm{c}}$} \\
\hline TCA $50 \%$, TCA $35 \%$ & Scalp & Single application & $66.1 \%[45]$ \\
\hline TCA 35\% + Jessner's solution & Face & Single application & $81.7 \%[45]$ \\
\hline GA $70 \%$ & Face & Single application & $15.8 \%[45]$ \\
\hline Tretinoin 5\% & Forearms & $\begin{array}{l}\text { Eight sequential applications every } \\
2 \text { weeks }\end{array}$ & NR [45] \\
\hline
\end{tabular}


Table 1 (continued)

\begin{tabular}{|c|c|c|c|}
\hline Active treatment & AK location/size of treatment area & Treatment regimen/procedure & Efficacy (complete clearance) ${ }^{\mathrm{a}}$ \\
\hline Phenol $100 \%$ & Face, scalp, extremities, trunk & $\begin{array}{l}\text { Once a month up to a maximum of } \\
8 \text { months }\end{array}$ & NR [45] \\
\hline $\begin{array}{l}\text { Laser therapy }{ }^{\mathrm{c}} \\
\mathrm{CO}_{2} \\
\text { Er: YAG laser }\end{array}$ & $\begin{array}{l}\text { Full-face skin resurfacing/clustered } \\
\text { AKs }\end{array}$ & $\begin{array}{l}\text { One application repeated according } \\
\text { to clinical response }\end{array}$ & NR \\
\hline Surgery ${ }^{\mathrm{c}}$ & $\begin{array}{l}\text { Face, scalp, trunk and extremities/ } \\
\text { single lesion }\end{array}$ & Deep shave or surgical excision & NR \\
\hline
\end{tabular}

5-FU 5-fluorouracil, $A K$ actinic keratosis, $A L A$ aminolevulinic acid, $E r: Y A G$ erbium-doped yttrium aluminum garnet, $G A$ glycolic acid, $I M Q$ imiquimod, $M A L$ methyl aminolevulinate, $N R$ not reported, $P D T$ photodynamic therapy, $S A$ salicylic acid, $T C A$ trichloroacetic acid, $T I W$ three times weekly

${ }^{a}$ These results refer to clinical studies with different follow-up schedules

${ }^{\mathrm{b}}$ Treatments are indicated for management of non-hyperkeratotic, non-hypertrophic, visible or palpable AKs (grade I, II); in case of grade III (hyperkeratotic lesions), pretreatment of lesions that reduces hyperkeratosis (i.e., with a keratolytic agent or physical removal) may be considered

${ }^{c}$ Procedures are recommended for all types of AK (grades I-III)

Fig. 2 Single actinic keratosis a before and $\mathbf{b}$ after local homebased 5\% imiquimod cream application three times weekly for 4 weeks

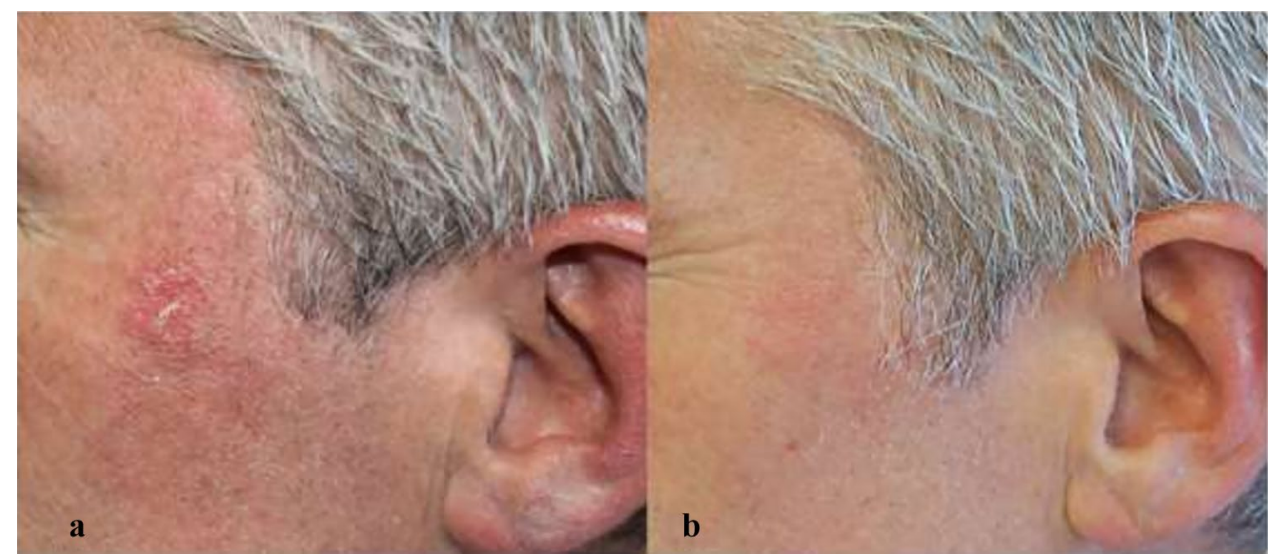

contact with eyes or mucosae, and patients should have close follow-up surveillance visits.

\subsection{5-Fluorouracil}

5-FU is a pyrimidine analogue, belonging to the family of antimetabolites. Its mechanism of action is based on the inhibition of thymidylate synthase, an enzyme needed for DNA synthesis and for the formation and function of RNA [49]. Various formulations of the drug are commercially available, including $5 \%$ cream or solution, $1 \%$ cream or solution, $2 \%$ solution, and $0.5 \%$ cream, that can be applied once or twice daily in the area of AK lesions for 2-4 weeks up to a maximum of 12 weeks. 5-FU is used to treat a single lesion or large areas, providing a complete clearance rate at 8 weeks ranging from $96 \%$ in patients treated with 5\% 5-FU to $48 \%$ in those receiving $0.5 \% 5$-FU cream $[53,54]$. Several studies have evaluated the efficacy and tolerability of such formulations. Three randomized controlled trials of 5\% 5-FU identified a range of $42.9-76.6 \%$ reductions of AK counts at 12-month follow-up [32, 34, $35]$. In two studies, complete clearance was achieved in 47.5 and $57.8 \%$ of patients, respectively, using the lower formulation of $0.5 \% 5$-FU cream applied once daily for 4 weeks compared with placebo $[55,56]$. A recent study evaluated the efficacy of four treatments (5\% imiquimod cream, methyl aminolevulinate PDT [MAL-PDT], 5\% 5-FU cream, and $0.015 \%$ ingenol mebutate gel [IGM]) for AK located on the head and neck. Results showed that 5\% 5-FU cream was the most effective among the fielddirected treatments. The primary outcome of the study was to identify the proportion of patients with a reduction of at least $75 \%$ of AK from baseline to 12 months after the end of treatment, thus defining the treatment success rate as the proportion of patients who remained free from treatment failure during this period. 5-FU was demonstrated to be superior (74.7\%) to imiquimod (53.9\%), MAL-PDT (37.7\%), and IGM (28.9\%), with no significant differences in tolerability between treatments [33]. In a network metaanalysis, 5\% 5-FU was likely to be more effective but less 
tolerated than cryosurgery and 3\% diclofenac sodium for the outcomes total clearance and lesion reduction from baseline [36].

Two novel 5-FU formulations were recently introduced for treatment of grade I-II AK in immunocompetent patients. The first was the 4\% 5-FU cream, which is an effective topical treatment applied once or twice daily for 2-4 weeks and has been demonstrated to have tolerability superior to that of 5\% 5-FU cream used twice daily [57]. The second formulation combined $0.5 \%$ solution 5 -FU with $10 \%$ salicylic acid (5-FU-SA) and was more effective than placebo for field treatment: the percentage of patients with complete clinical clearance was up to 49.5 and $18.2 \%$, respectively, when the drug was applied once daily for 12 weeks to a total maximum area of $25 \mathrm{~cm}^{2}$, for AK located on the face and balding scalp [58]. In a single randomized phase III trial, 5-FU-SA was superior to 3\% diclofenac gel in hyaluronic acid, as measured by histological clearance (72 vs. $59.1 \%$ ) and by complete clinical clearance $(55.4$ vs. $32.0 \%$ ) [59]. Moreover, topical application of 5-FU-SA resulted in successful treatment for AK on distal extremities and had a good safety profile [37].

Side effects with 5-FU include inflammation, pain, burning, crusting, and erosions but rarely affect patient adherence to therapy [36]. No specific studies or subanalyses on the use of 5-FU have been performed in elderly patients, but no dosage adjustment is needed in this specific population. However, close monitoring is recommended for patients with diabetes with decreased tactile, pain, and temperature perception. In addition, antiviral drugs (e.g., brivudine), phenytoin, and methotrexate may increase the rate of side effects.

\subsection{3\% Diclofenac in Hyaluronic Acid}

Diclofenac is a nonsteroidal anti-inflammatory drug that blocks the enzyme cyclooxygenase 2 , the main functions of which are promoting tumor growth, cell proliferation, and angiogenesis and inhibiting cellular apoptosis [60]. A single formulation of $3 \%$ diclofenac gel in $2.5 \%$ hyaluronic acid is available for the treatment of AK on the face/scalp, targeting clustered lesions and FC. The recommended therapeutic regimen, consisting of twice-daily application for 60-90 days, provides a complete clearance response rate of $41 \%$ at the end of the treatment, rising to $58 \%$ at 30 -day follow-up after therapy [60]. A Cochrane systematic review [61] found a similar efficacy for this drug compared with other topical therapies (5-FU, 5\% imiquimod, and IGM) in terms of complete clearance, and another study [62] reported good tolerability and a favorable pharmacoeconomic profile.
Thus, it should be considered for FC treatment. Its main adverse events are pruritus, erythema, localized edema, and dry skin, leading to a low proportion of patients (3.9-6.1\%) withdrawing from therapy [63]. Of note, it should be avoided in patients with asthma that is exacerbated by nonsteroidal anti-inflammatory drugs [38].

In our experience, both elderly and middle-aged patients whose work sees them in direct contact with the public are good candidates for treatment with diclofenac because of its safety profile and lower rate of adverse events compared with other topical drugs, although adherence may be an issue of concern. However, patients appreciate the lack of side effects and are willing to repeat treatment cycles if needed.

\subsection{Piroxicam}

Piroxicam is a nonsteroidal anti-inflammatory drug with a mechanism of action similar to that of diclofenac. It is a potent cyclooxygenase- 1 inhibitor and suppresses important proteinases involved in tumor growth [64]. A topical formulation containing $0.8 \%$ piroxicam and a broad-spectrum sunscreen applied twice daily for 6 months resulted in significant improvement of AK. Indeed, 55\% of patients (95\% confidence interval [CI] 43-66) experienced a complete response, with clearance maintained 1-year post-treatment [64]. Adverse events were limited to local irritation [25]. Controlled trials are needed to establish the efficacy and tolerability of this topical treatment compared with standard treatments and to evaluate the antiviral effects of this drug in human papillomavirus (HPV)-associated AK [25].

\subsection{Tirbanibulin}

Tirbanibulin is a non-adenosine triphosphate competitive Src kinase agent inhibitor that blocks tubulin polymerization in actively dividing cells [39]. A phase II study comparing once-daily application of $1 \%$ tirbanibulin ointment to AK of the face and scalp over a $25 \mathrm{~cm}^{2}$ area for 3 or 5 consecutive days reported better outcomes with the 5-day treatment [39]. This was the selected regimen for two identically designed double-blind phase III trials in which patients were assigned to receive either topical $1 \%$ tirbanibulin or vehicle (placebo) ointment once daily. In these studies, the outcomes obtained in the interventional arms were superior to those for vehicle at 2 months, with complete clearance ranging from 44 to $54 \%$ of subjects, although most patients developed transient local reactions, and lesions recurred in half of them at 1 year [65]. Recently, the US FDA announced the approval of the drug for the topical treatment of $\mathrm{AK}$ and $\mathrm{FC}$ on the face or scalp [66]. 


\section{Physician-Managed Treatments}

AK treatments such as cryosurgery, chemical peeling, and conventional and daylight PDT are managed by the physician, which may overcome several issues with home-based treatments. These procedures are usually less time consuming than topical treatments and are performed under the supervision of a healthcare professional but require access to a dermatological center.

\subsection{Cryotherapy}

Cryotherapy with liquid nitrogen is a lesion-directed approach widely used for isolated lesions and is performed in an office-based setting without anesthesia; it is generally well tolerated [67]. Using a spray device or a cotton tip applicator, liquid nitrogen at a temperature of $-196{ }^{\circ} \mathrm{C}$ is applied in one to three freeze-thaw cycles, establishing intracellular and extracellular ice crystal formation and thereby damaging AK cells through cryolysis, vascular stasis, and apoptosis [40]. The reported complete clearance rate with cryosurgery ranges from 39 to $76 \%$, and higher efficacy has been reported when cryosurgery is combined with other topical treatment [68]. In particular, the association with $3.75 \%$ or $5 \%$ imiquimod cream, $0.5 \%$ or $5 \% 5$-FU cream, 5-FU-SA, 3\% diclofenac in 2.5\% hyaluronic acid, and PDT with aminolevulinic acid (ALA) or its methyl ester led to a lesion-specific reduction ranging from 73.2 to $89 \%$, with tolerability similar to that with cryosurgery alone [69-72]. The wide variability of cryosurgery efficacy may be due to different cryosurgery techniques and schedules such as the number of freeze-thaw cycles and the distance from the spray to the tip of the AK, as well as a lack of morphologic discrimination among thin/thicker AK considered in the studies [73, 74]. Mild pain, stinging and burning, erythema, and blistering are the more common side effects that may appear during the treatment or be mentioned by the patient; they resolve spontaneously approximately a few days after the procedure [73]. A post-inflammatory localized hypopigmented patch may develop as a sequela of the procedure, especially in individuals with dark skin [75]. Extensive cryosurgery over large areas has been referred to as "cryopeeling," and this can be used to treat multiple AK lesions within FC with the aim of also treating the background damage $[75,76]$.

\subsection{Photodynamic Therapy}

PDT is a minimally invasive procedure that exerts a selective cytotoxic effect toward malignant cells. Using photosensitizing agents such as 5-ALA and 5-ALA methyl ester (5-MAL), which selectively accumulate in atypical epidermal keratinocytes, reactive oxygen species are generated through photochemical and photophysical processes, leading to direct cellular damage, necrosis or apoptosis, and vascular endothelial damage [75, 41]. Conventional-PDT (c-PDT) is an effective therapeutic option to treat the FC, with higher response rates (69-93\%) observed in the face and scalp than on the forearm and hands (44-80\%) [77]. A recurrence rate of up to $24 \%$ has been reported at 12 months [78].

In recent years, daylight-PDT (dl-PDT), consisting of application of a photosensitizer followed by exposure to daylight for $2 \mathrm{~h}$, has been shown to provide clinical benefits similar to those observed with c-PDT [43, 44, 79]. The dl-PDT uses natural light with a wavelength of approximately $380-780 \mathrm{~nm}$. The incubation time of the photosensitizer with dl-PDT is 30 minutes, compared with $1-3 \mathrm{~h}$ with c-PDT. After 30 minutes, the patient is exposed to the daylight, allowing for a lower and more continuous rate of production and activation of the protoporphyrin IX (pPIX). This continuous activation, rather than the rapid activation of large amounts of pPIX by blue or red light, may explain the lower pain intensity associated with dl-PDT. In most European countries, dl-PDT can be performed from April to September, with a temperature $>10^{\circ} \mathrm{C}$, and cloudy or overcast but not rainy conditions [43]. Using daylight as an irradiation source is not realistic in specific outside settings (e.g., low temperatures or rain), and this procedure may be not adequate for all patients or all anatomical sites (e.g., lower extremities) [80]. Complete clearance with dl-PDT has been reported in 70-89\% of cases, and the long-term efficacy of this treatment modality shows a low recurrence rate, varying from 8.7 to $13 \%$ at 12 months. To implement the feasibility of dl-PDT, particularly in countries with rainy weather conditions, alternative artificial light sources were considered for AK treatment. Options included a greenhouse (to provide a comfortable atmosphere regardless of outdoor temperatures) or artificial sources of white light [81, 82, 42].

In addition, the 5-ALA patch is currently licensed in Europe for c-PDT, focusing on up to a maximum of six $(\leq 1.8$ $\mathrm{cm}) \mathrm{AK}$ on the face and bald scalp. A multicenter real-world clinical study with 5-ALA patch PDT to treat AK of the face, scalp, and/or upper extremities showed complete response in $87 \%$ of grade I AK and in $47 \%$ of grade II-III lesions. The lower response rate for grade II-III lesions was in line with responses observed with other photosensitizers used in c-PDT or dl-PDT [83].

PDT is easily performed in a physician's office or the outpatient setting, allowing a timetable to be scheduled and monitoring of the overall procedure with comprehensive management. Local skin reactions such as erythema, pain, burning, edema, itching, desquamation, and pustule development are commonly observed during irradiation and in the hours/days immediately after therapy. Notably, pain is a short-term complication that is more frequent during c-PDT than dl-PDT and that can adversely affect long-term 
patient satisfaction. Rare adverse events include urticaria, contact dermatitis at the site of photosensitizer application, and erosive pustular dermatosis. Mordon et al. [84] proposed a new protocol that is as efficient as the conventional one, named phosistos protocol (P-PDT), which includes illumination with a tissue-based biophotonic device, resulting in a procedure that is less painful than c-PDT and more available regardless of environmental conditions than dl-PDT [84]. Finally, to overcome the technological limits of currently available instruments, new sources, light-based devices, improved photosensors, measurement devices, and innovative application strategies are being investigated $[42,85]$.

\subsection{Chemical Peelings}

Chemical peelings have been used for the treatment of multiple or clustered lesions and FC [86, 45]. A recent metaanalysis summarized the results of eight studies to assess the efficacy of different chemical peelings. The use of trichloroacetic acid (TCA) plus Jessner's solution showed lower lesion clearance (risk ratio [RR] 0.92; 95\% CI 0.85-0.99; one study; $p=0.03$ ) compared with 5 -FU $5 \%$ cream monotherapy; at the same time, the study reported a significantly higher clearance rate of AK with the combination of 5\% 5-FU and 70\% glycolic acid than with 70\% glycolic acid monotherapy (RR 5.87; 95\% CI 4.39-7.85; one study; $p<0.001)$. Moreover, 50 and $30 \%$ TCA as monotherapy showed lower efficacy than cPDT [87].

\subsection{Laser Therapy}

Laser therapies play a role in the treatment of single AK lesions and FC, removing the epidermis and papillary dermis containing actinic damage or inducing a full-face skin resurfacing. As monotherapy, despite long healing times, fully ablative laser resurfacing with carbon dioxide and erbiumdoped yttrium aluminum garnet have been found to be more effective than fractional ablative techniques for the treatment of AK [43]. Although clinical trials with large sample sizes are needed, data from the literature suggest that laser resurfacing monotherapy is less effective than PDT and as effective as 5-FU and 30\% TCA [88]. The rate of response to treatment is approximately $90 \%$, and the rate of recurrence at 6 months is $10-15 \%$ [43]. Limitations of the treatment are related to the cost and possible local skin reactions other than pain, inflammation, pigmentary changes, and delayed skin healing. Both ablative and fractional lasers can be combined with other therapies, such as local agents, to achieve a more effective procedure. A recent review reported that laser therapy appears to be a valid therapeutic option among the nonsurgical approaches in the treatment of actinic cheilitis [89].

\subsection{Surgery}

Surgical excision or a biopsy of AK should always be considered in cases of diagnostic uncertainty or treatment-resistant lesions [90]. In such instances, histological examination may be useful to rule out an incipient invasive cutaneous SCC, and deep shave or surgical excision should be preferred to include the deep skin layers to establish the presence of dermal invasion [75].

\subsection{Combined Therapies}

The sequential use of different agents or procedures to increase efficacy and possibly decrease side effects has been investigated [91]. However, combined treatment may lead to more complicated procedures that are not always easily accepted or understood by patients, potentially leading to lower treatment adherence. A number of studies investigated a combined therapy focused on PDT associated with topical therapies such as imiquimod, 5-FU, IGM, tazarotene gel, and calcipotriol ointment or with physical treatments such as cryosurgery, microneedling, or laser [91, 92]. However, the quality of evidence ranged from low to very low for outcomes in both field- and lesion-directed therapy, so we cannot assume a greater efficacy and safety of topical treatments combined with PDT compared with monotherapy [92]. Treatment with cryotherapy followed by topical therapies (imiquimod, IGM, 3\% diclofenac, 0.5\% 5-FU cream, and PDT) for field- and lesion-treatment resulted in higher complete clearance rates than did monotherapy, although the quality of evidence for these results was estimated as low, with a limited confidence in the effect estimated [92]. An interesting alternative approach would be initial treatment with a topical agent, therefore combining it with cryosurgery, especially for difficult-to-treat AK, with the aim to reduce the hypopigmentation sequelae of cryosurgery. To our knowledge, no studies have yet evaluated the suitable benefits of the latter combination.

Surgical excision-either shave or complete excisionis indicated to promote the absorption of subsequent topical drugs applied in hyperkeratotic AK [68]. A case series in organ transplant recipients reported complete and partial AK response with curettage pre-treatment of multiple refractory AK lesions preceding topical treatment with 5\% 5-FU and PDT [93]. When curettage, SA, or $40 \%$ urea cream followed by PDT were compared, curettage achieved higher response rates, with patients experiencing significantly less pain [94]. 


\section{Recent Studies and Ongoing Clinical Trials with Topical Treatments}

A number of novel agents are under development with the aim to increase the clearance rate and to reduce local adverse events compared with current AK treatments. The main pharmacologic approaches follow the potential link between $\mathrm{HPV}$-associated AK and target proto-oncogenes supporting the biology of these tumors $[95,96]$.

\subsection{Resiquimod}

Resiquimod is a topical immune-response modifier that promotes the activation of myeloid dendritic cells and plasmacytoid dendritic cells through a direct mechanism on both TLR7 and TLR8. Based on its pharmacodynamic profile, this drug potentially achieves a higher potency (10-100 times) than imiquimod for the treatment of AK, with a higher production of interleukin-12 and tumor necrosis factor [50]. Four different concentrations $(0.01 \%, 0.03 \%$, $0.06 \%$, and $0.1 \%$ ) of resiquimod gel were investigated in a phase II study with a dosing regimen of three times per week for 4 weeks in one or two treatment cycles. A high efficacy rate was reported in all study groups (complete clearance rates ranging from 77.1 to $90.3 \%$ ), with side effects only observed at higher concentrations [97]. Therapy with $0.01 \%$ resiquimod gel had the broadest therapeutic window, with a clearance rate of $77 \%$ and severe erythema in $17 \%$ of patients [97]. These results were supported by a prospective, randomized, partly placebo-controlled, double-blind phase II study, wherein efficacy was significantly higher in all resiquimod treatment groups than with placebo [98]. As expected with the use of an immune-stimulatory therapy, erythema and scabbing were the most common local adverse reactions [97-99]. Future data comparing resiquimod and standard topical therapy are required to define the role of this drug in AK therapy.

\subsection{Potassium Dobesilate}

Potassium dobesilate is an endothelial stabilizing agent that acts on the inhibition of vascular endothelial growth factor and fibroblast growth factor. The results of a phase II clinical trial evaluating efficacy and safety that was completed in 2018 (NCT03210740) were never released, and it is unclear whether this drug is still under development for AK [100].

\subsection{Betulinic Acid}

Betulinic acid has shown anti-cancer effects through the induction of apoptotic cell death and antiangiogenic activity. A multicenter placebo-controlled study evaluating the efficacy and tolerability of betulinic acid failed to show superiority to placebo [101].

\subsection{Paclitaxel}

Paclitaxel, under development as a nanoparticle formulation in ointment, is a beta tubulin antagonist (class I) targeting fast proliferating cells in active division. A phase II randomized, double-blind clinical trial (NCT03083470) investigated the safety, tolerability, and efficacy of four different dosages of the product. Although the trial was completed in 2018, the results have not been published.

\subsection{Celecoxib}

A topical formulation containing celecoxib, a nonsteroidal anti-inflammatory drug, was tested in an interventional trial in 2019 (NCT03116698). Different concentrations of the products were applied once or twice daily, with the main outcomes assessed after 16 weeks (12 weeks' treatment and a 4-week treatment-free follow-up period). Since no results have been provided, its clinical utility requires further investigation.

\subsection{Potassium Hydroxide}

An ongoing, three-armed, randomized, double-blind phase III study is evaluating the efficacy and tolerability of 5\% potassium hydroxide, a keratolytic agent, versus $3 \%$ diclofenac gel and placebo (NCT04552327).

\section{Discussion}

A number of features can affect the choice of AK treatment. When deciding a specific therapeutic approach, it is important to consider a variety of factors, including treatment duration, cosmetic outcome, patient compliance, local adverse reactions, treatment cost, and risk factors for recurrence. First, we recommend clear physician-patient communication that starts with an explanation of the chronic nature of $\mathrm{AK}$, clarifying that a very small percentage of AK may evolve into invasive SCC, thus suggesting treatment of any AK regardless of clinical grading [102]. The ideal AK treatment should clear both clinical and subclinical lesions across the whole FC, and patient adherence represents a crucial factor in their management. As elderly individuals with chronic diseases and multiple morbidities represent a remarkable proportion of the population, interventions to increase medication adherence are important [103].

A multicenter, prospective, real-life study that focused on patient-reported outcomes in AK revealed that effective 
physician-patient communication may buffer therapyrelated distress, improving patient quality of life, treatment satisfaction, and adherence [104]. However, as reported in a multicenter clinical consensus, the terminology used by the physician is crucial and differs according to the patient's ability to understand, social background, or cognitive decline [20]. In the latter case, the role of a family member or caregiver is fundamental.

An additional important issue is ensuring that the patient fully understands the type and role of local skin reactions to the treatment and, with some drugs such as imiquimod, value them as a positive sign of treatment effectiveness. The choice of patient-managed treatments requires appropriate education and information about the best strategies for the patient and/or family members to manage adverse events. To prevent or treat mild local skin reactions, it may be helpful to suggest the use of soothing and moisturizing agents in combination with therapies. If local reactions are severe, treatment discontinuation may be recommended. Therefore, the use of photographic documentation is suggested at baseline and during treatment to document both clinical benefit and local adverse events. Physician-managed treatments have the advantage of a precise selection of $\mathrm{AK}$, whereas home-based treatments have the limitation that the patient is often unable to identify the specific AK to be treated. To overcome this problem, photographic documentation represents a useful tool to allow the patient to properly manage the topical treatment. In patients with limited life expectancy or for whom the morbidity of treatment outweighs the potential benefits, a "wait and see" strategy may be considered.

Finally, new treatment options are directed toward personalized treatment, taking into consideration the characteristics of both patients and lesions as well as the genetic basis and individual risk of developing an invasive cutaneous SCC. Other factors, such as a close correlation between HPV infection and the development of $\mathrm{AK}$, as well as ongoing research on prognostic genetic markers to reveal high-risk AK, could potentially lead to further treatment options [96].

\section{Declarations}

Funding No funding was provided for this manuscript.

Conflicts of interest Laura Del Regno, Silvia Catapano, Alessandro Di Stefani and Simone Cappilli have no conflicts of interest that are directly relevant to the content of this article. Ketty Peris has received grants and personal fees from Almirall, AbbVie, Biogen, Lilly, Celgene, Galderma, Leo Pharma, Novartis, Pierre Fabre, Sanofi, Sandoz, Sun Pharma, and Janssen, outside the submitted work.

Availability of data and material Not applicable.

Code availability Not applicable.
Ethics approval Not applicable

Consent to participate Not applicable.

Consent for publication Not applicable.

Author contributions LDR, SCat, and KP contributed substantially to the conception of the paper and the acquisition and analysis of data. LDR and SCap drafted the manuscript. ADS and KP reviewed it critically and approved the final version for publication. All authors are responsible for the accuracy and integrity of any part of the work.

Open Access This article is licensed under a Creative Commons Attribution-NonCommercial 4.0 International License, which permits any non-commercial use, sharing, adaptation, distribution and reproduction in any medium or format, as long as you give appropriate credit to the original author(s) and the source, provide a link to the Creative Commons licence, and indicate if changes were made. The images or other third party material in this article are included in the article's Creative Commons licence, unless indicated otherwise in a credit line to the material. If material is not included in the article's Creative Commons licence and your intended use is not permitted by statutory regulation or exceeds the permitted use, you will need to obtain permission directly from the copyright holder. To view a copy of this licence, visit http://creativecommons.org/licenses/by-nc/4.0/.

\section{References}

1. Heaphy MR Jr, Ackerman AB. The nature of solar keratosis: a critical review in historical perspective. J Am Acad Dermatol. 2000;43:138-50. https://doi.org/10.1067/mjd.2000.107497.

2. Werner RN, Sammain A, Erdmann R, et al. The natural history of actinic keratosis: a systematic review. Br J Dermatol. 2013;169:502-18. https://doi.org/10.1111/bjd.12420.

3. Ackerman AB, Mones JM. Solar (actinic) keratosis is squamous cell carcinoma. Br J Dermatol. 2006;155:9-22. https://doi.org/ 10.1111/j.1365-2133.2005.07121.x.

4. Feldman SR, Fleischer AB Jr. Progression of actinic keratosis to squamous cell carcinoma revisited: clinical and treatment implications. Cutis. 2011;87:201-7.

5. Ferrandiz C. Update on actinic keratosis in clinical trial experience with imiquimod. Br J Dermatol. 2007;157:32-3. https://doi. org/10.1111/j.1365-2133.2007.08270.x.

6. Lai V, Cranwell W, Sinclair R. Epidemiology of skin cancer in the mature patient. Clin Dermat. 2018;36:167-76. https://doi. org/10.1016/j.clindermatol.2017.10.008.

7. Fargnoli MC, Altomare G, Benati E, et al. Prevalence and risk factors of actinic keratosis in patients attending Italian dermatology clinics. Eur J Dermatol. 2017;27:599-608. https://doi.org/ 10.1684/ejd.2017.3126.

8. Frost C, Williams G, Green A. High incidence and regression rates of solar keratoses in a queensland community. J Invest Dermatol. 2000;115:273-7. https://doi.org/10.1046/j.1523-1747. 2000.00048.x.

9. Bernard P, Dupuy A, Sasco A, et al. Basal cell carcinomas and actinic keratoses seen in dermatological practice in France: a cross sectional survey. Dermatology. 2008;216:194-9. https:// doi.org/10.1159/000112925.

10. Eder J, Prillinger K, Korn A, et al. Prevalence of actinic keratosis among dermatology outpatients in Austria. Br J Dermatol. 2014;171:1415-21. https://doi.org/10.1111/bjd.13132. 
11. Flohil SC, Van der Leest RJ, Dowlatshahi EA, et al. Prevalence of actinic keratosis and its risk factors in the general population: the Rotterdam Study. J Investig Dermatol. 2013;133:1971-8. https:// doi.org/10.1038/jid.2013.134.

12. Ferrándiz C, Plazas MJ, Sabaté M, Palomino R, EPIQA Study Group. Prevalence of actinic keratosis among dermatology outpatients in Spain. Actas Dermosifiliogr 2016;107:674-680. https://doi.org/10.1016/j.ad.2016.05.016

13. Dirschka T, Gupta G, Micali G, et al. Real-world approach to actinic keratosis management: practical treatment algorithm for office-based dermatology. J Dermatol Treat. 2017;28:431-42. https://doi.org/10.1080/09546634.2016.1254328.

14. Memon AA, Tomenson JA, Bothwell J, Friedmann PS. Prevalence of solar damage and actinic keratosis in a Merseyside population. Br J Dermatol. 2000;142:1154-9. https://doi.org/ 10.1046/j.1365-2133.2000.03541.x.

15. Olsen EA, Abernethy ML, Kulp-Shorten C, et al. A doubleblind, vehicle controlled study evaluating masoprocol cream in the treatment of actinic keratoses on the head and neck. J Am Acad Dermatol. 1991;24:738-43. https://doi.org/10.1016/ 0190-9622(91)70113-g.

16. Schmitz L, Kahl P, Majores M, et al. Actinic keratosis: correlation between clinical and histological classification systems. J Eur Acad Dermatol Venereol. 2016;30:1303-7. https://doi. org/10.1111/jdv.13626.

17. Fernandez Figueras MT. From actinic keratosis to squamous cell carcinoma: pathophysiology revisited. J Eur Acad Dermatol Venereol. 2017;31:5-7. https://doi.org/10.1111/jdv.14151.

18. Fernández-Figueras MT, Carrato C, Sáenz X, et al. Actinic keratosis with atypical basal cells (AK I) is the most common lesion associated with invasive squamous cell carcinoma of the skin. J Eur Acad Dermatol Venereol. 2015;29:991-7. https:// doi.org/10.1111/jdv.12848.

19. Fernández-Figueras MT, Saenz-Sardà X, Vargas P, et al. The depth of follicular extension in actinic keratosis correlates with the depth of invasion in squamous cell carcinoma: implication for clinical treatment. J Eur Acad Dermatol Venereol. 2018;32:1657-61. https://doi.org/10.1111/jdv.14901.

20. Philipp-Dormston WG, Battistella M, Boussemart L, et al. Patient-centered management of actinic keratosis. Results of a multi-center clinical consensus analyzing non-melanoma skin cancer patient profiles and field-treatment strategies. J Dermatolog Treat. 2020;31:576-82. https://doi.org/10.1080/ 09546634.2019.1679335.

21. Willenbrink TJ, Ruiz ES, Cornejo CM, et al. Field cancerization: Definition, epidemiology, risk factors, and outcomes. J Am Acad Dermatol. 2020;83:709-17. https://doi.org/10. 1016/j.jaad.2020.03.126.

22. Javor S, Gasparini G, Biatta CM, et al. P53 staining index and zonal staining patterns in actinic keratoses. Arch Dermatol Res. 2021;313:275-9. https://doi.org/10.1007/s00403-020-02104-y.

23. Tang Z, Kang L, Zhang Y, et al. The diagnostic value of in vivo reflectance confocal microscopy in actinic keratosis. Res Technol. 2021;27:80-5. https://doi.org/10.1111/srt.12913.

24. Moscarella E, Di Brizzi EV, Casari A, et al. Italian expert consensus paper on the management of patients with actinic keratoses. Dermatol Ther. 2020;33: e13992. https://doi.org/10. 1111/dth.13992.

25. De Oliveira ECV, Da Motta VRV, Pantoja PC, et al. Actinic keratosis-review for clinical practice. Int J Dermatol. 2019;58:400-7. https://doi.org/10.1111/ijd.14147.

26. Hansen JB, Larsson T, Dunkelly-Allen N, et al. Real-World effectiveness and safety of field- and lesion-directed treatments for actinic keratosis. J Drugs Dermatol. 2020;19:756-62. https://doi.org/10.36849/JDD.2020.5123.

27. Alomar A, Bichel J, McRae S. Vehicle-controlled, randomized, double-blind study to assess safety and efficacy of imiquimod $5 \%$ cream applied once daily 3 days per week in one or two courses of treatment of actinic keratoses on the head. Br J Dermatol. 2007;157:133-41. https://doi.org/10.1111/j.1365-2133. 2007.07942.x.

28. Jorizzo J, Dinehart S, Matheson R, et al. Vehicle-controlled, double-blind, randomized study of imiquimod 5\% cream applied 3 days per week in one of two courses of treatment for actinic keratoses on the head. J Am Acad Dermatol. 2007;57:265-8. https://doi.org/10.1016/j.jaad.2007.01.047.

29. Hanke CW, Beer KR, Stockfleth E, et al. Imiquimod $2.5 \%$ and $3.75 \%$ for the treatment of actinic keratoses: results of two placebo-controlled studies of daily application to the face and balding scalp for two 3-week cycles. J Am Acad Dermatol. 2010;62(4):573-81.

30. Swanson N, Abramovits W, Berman B, et al. Imiquimod 2.5\% and $3.75 \%$ for the treatment of actinic keratoses: results of two placebo-controlled studies of daily application to the face and balding scalp for two 2-week cycles. J Am Acad Dermatol. 2010;62(4):582-90.

31. Hanke CW, Swanson N, Bruce S, et al. Complete clearance is sustained for at least 12 months after treatment of actinic keratoses of the face or balding scalp via daily dosing with imiquimod $3.75 \%$ or $2.5 \%$ cream. J Drugs Dermatol. 2011;10(2):165-70.

32. Dréno B, Cerio R, Dirschka T, et al. A novel actinic keratosis field assessment scale for grading actinic keratosis disease severity. Acta Derm Venereol. 2017;97:1108-13.

33. Jansen MHE, Kessels JPHM, Nelemans PJ, et al. Randomized trial of four treatment approaches for actinic keratosis. N Engl J Med. 2019;380:935-46. https://doi.org/10.1056/NEJMoa1811 850 .

34. Krawtchenko N, Roewert-Huber J, Ulrich M, et al. A randomised study of topical $5 \%$ imiquimod vs topical 5 -fluorouracil vs cryosurgery in immunocompetent patients with actinic keratoses: a comparison of clinical and histological outcomes including 1-year follow-up. Br J Dermatol. 2007;157:34-40.

35. Askew DA, Mickan SM, Soyer HP, et al. Effectiveness of 5-fluorouracil treatment for actinic keratosis-a systematic review of randomized controlled trials. Int J Dermatol. 2009;48:453-63.

36. Wu Y, Tang N, Cai L, et al. Relative efficacy of 5-fluorouracil compared with other treatments among patients with actinic keratosis: a network meta-analysis. Dermatol Ther. 2019;32: e12822. https://doi.org/10.1111/dth.12822.

37. Iglesias-Puzas A, Batalla A, Suh-Oh HJ, et al. 0.5\% 5-fluorouracil $/ 10 \%$ salicylic acid for the treatment of distal actinic keratoses under daily practice conditions. J Drugs Dermatol. 2019;18:285-8.

38. Tan JHY, Hsu AAL. Nonsteroidal anti-inflammatory drug (NSAID) exacerbated respiratory disease phenotype: topical NSAID and asthma control-a possible oversight link. Respir Med. 2016;118:1-3. https://doi.org/10.1016/j.rmed.2016.07.004.

39. Kempers S, DuBois J, Forman S, et al. Tirbanibulin ointment $1 \%$ as a novel treatment for actinic keratosis: phase 1 and 2 results. J Drugs Dermatol. 2020;19(11):1093-100. https://doi.org/10. 36849/JDD.2020.5576.

40. Clebak KT, Mendez-Miller M, Croad J. Cutaneous cryosurgery for common skin conditions. Am Fam Phys. 2020;101:399-406.

41. Heppt MV, Leiter U, Steeb T, et al. S3 guideline for actinic keratosis and cutaneous squamous cell carcinoma-short version, part 1: diagnosis, interventions for actinic keratoses, care 
structures and quality-of-care indicators. J Dtsch Dermatol Ges. 2020;18:275-94. https://doi.org/10.1111/ddg.14048.

42. Maire C, Vignion-Dewalle AS, Cartier H, et al. Artificial white light photodynamic therapy for actinic keratosis: a study of 38 patients in private office practice. J Eur Acad Dermatol Venereol. 2020;34:165-7. https://doi.org/10.1111/jdv.16112.

43. Dianzani C, Conforti C, Giuffrida R, et al. Current therapies for actinic keratosis. Int J Dermatol. 2020;59:677-84. https://doi. org/10.1111/ijd.14767.

44. Rubel DM, Spelman L, Murrell DF, et al. Daylight photodynamic therapy with methyl aminolevulinate cream as a convenient, similarly effective, nearly painless alternative to conventional photodynamic therapy in actinic keratosis treatment: a randomized controlled trial. Br J Dermatol. 2014;171:1164-71. https://doi. org/10.1111/bjd.13138.

45. Witheiler DD, Lawrence N, Cox SE, et al. Long-term efficacy and safety of Jessner's solution and 35\% trichloroacetic acid vs $5 \%$ fluorouracil in the treatment of widespread facial actinic keratoses. Dermatol Surg. 1997;23:191-6. https://doi.org/10.1111/j. 1524-4725.1997.tb00020.x.

46. Esmann S, Jemec GB. Patients' perceptions of topical treatments of actinic keratosis. J Dermatol Treat. 2014;25:375-9. https://doi. org/10.3109/09546634.2012.757285.

47. Erntoft S, Norlin J, Pollard C, Diepgen T. Patient-reported adherence and persistence to topical treatments for actinic keratosis: a longitudinal diary study. Br J Dermatol. 2016;175(5):1094-6.

48. Shergill B, Zokaie S, Carr AJ. Non-adherence to topical treatments for actinic keratosis. Patient Prefer Adherence. 2013;17(8):35-41. https://doi.org/10.2147/PPA.S47126.PMID: 24379656;PMCID:PMC3872140.

49. Micali G, Lacarrubba F, Nasca MR, et al. Topical pharmacotherapy for skin cancer: part I. Pharmacology. J Am Acad Dermatol. 2014;70(965):e1-12. https://doi.org/10.1016/j.jaad.2013.12.045.

50. Bubna AK. Imiquimod-its role in the treatment of cutaneous malignancies. Indian J Pharmacol. 2015;47(4):354-9. https://doi. org/10.4103/0253-7613.161249.

51. Swanson N, Smith CC, Kaur M, et al. Imiquimod $2.5 \%$ and $3.75 \%$ for the treatment of actinic keratoses: two phase 3, multicenter, randomized, double-blind, placebo-controlled studies. J Drugs Dermatol. 2014;13:166-9.

52. Emmerich VK, Cull D, Kelly KA, et al. Patient assessment of 5 -fluorouracil and imiquimod for the treatment of actinic keratoses: a retrospective study of real-world effectiveness. J Dermatol Treat. 2021;2021:1-4. https://doi.org/10.1080/09546634. 2021.1917758.

53. Peris K, Calzavara-Pinton PG, Neri L, et al. Italian expert consensus for the management of actinic keratosis in immunocompetent patients. J Eur Acad Dermatol Venereol. 2016;30:1077-84. https://doi.org/10.1111/jdv.13648.

54. Ezzedine K, Painchault C, Brignone M. Use of complete clearance for assessing treatment efficacy for 5-fluorouracil interventions in actinic keratoses: how baseline lesion count can impact this outcome. J Mark Access Health Policy. 2020;8:1829884. https://doi.org/10.1080/20016689.2020.1829884.

55. Jorizzo J, Stewart D, Bucko A, et al. Randomized trial evaluating a new $0.5 \%$ fluorouracil formulation demonstrates efficacy after 1-, 2-, or 4-week treatment in patients with actinic keratosis. Cutis. 2002;70:335-9.

56. Weiss J, Menter A, Hevia O, et al. Effective treatment of actinic keratosis with $0.5 \%$ fluorouracil cream for 1,2 , or 4 weeks. Cutis. 2002;70:22-9.

57. Dohil MA. Efficacy, safety, and tolerability of $4 \% 5$-fluorouracil cream in a novel patented aqueous cream containing peanut oil once daily compared with 5\% 5-fluorouracil cream twice daily: meeting the challenge in the treatment of actinic keratosis. $\mathrm{J}$ Drugs Dermatol. 2016;15:1218-24.
58. Stockfleth E, von Kiedrowski R, Dominicus R, et al. Efficacy and safety of 5 -fluorouracil $0.5 \%$ salicylic acid $10 \%$ in the fielddirected treatment of actinic keratosis: a phase III, randomized, double-blind, vehicle-controlled trial. Dermatol Ther Heidelb. 2017;7:81-96.

59. Stockfleth E, Kerl H, Zwingers T, et al. Low-dose 5-fluorouracil in combination with salicylic acid as a new lesion-directed option to treat topically actinic keratoses: histological and clinical study results. Br J Dermatol. 2011;165:1101-8. https://doi. org/10.1111/j.1365-2133.2011.10387.x.

60. Nelson C, Rigel D, Smith S, et al. Phase IV, open-label assessment of the treatment of actinic keratosis with 3.0\% diclofenac sodium topical gel (Solaraze). J Drugs Dermatol. 2004;3:401-7.

61. Gupta AK, Paquet M, Villanueva E, et al. Interventions for actinic keratoses. Cochrane Database Syst Rev. 2012;12:CD004415. https://doi.org/10.1002/14651858.CD004415.pub2.

62. Nisticò S, Del-Duca E, Torchia V, et al. Cost-efficacy analysis of $3 \%$ diclofenac sodium, ingenol mebutate, and $3.75 \%$ imiquimod in the treatment of actinic keratosis. Int J Immunopathol Pharmacol. 2018;32:925. https://doi.org/10.1177/2058738418757925.

63. Steeb T, Wessely A, Harlaß M, et al. A systematic review and meta-analysis of interventions for actinic keratosis from postmarketing surveillance trials. J Clin Med. 2020;9:2253. https:// doi.org/10.3390/jcm9072253.

64. Babino G, Diluvio L, Bianchi L, et al. Long-term use of a new topical formulation containing piroxicam $0.8 \%$ and sunscreen: efficacy and tolerability on actinic keratosis. A proof of concept study. Curr Med Res Opin. 2016;32:1345-9. https://doi.org/10. 1080/03007995.2016.1174678.

65. Blauvelt A, Kempers S, Lain E, et al. Phase 3 trials of tirbanibulin ointment for actinic keratosis. N Engl J Med. 2021;384:51220. https://doi.org/10.1056/NEJMoa2024040.

66. Markham A, Duggan S. Tirbanibulin: first approval. Drugs. 2021;81:509-13.

67. Noels EC, Hollestein LM, Van Egmond S, et al. Healthcare utilization and management of actinic keratosis in primary and secondary care: a complementary database analysis. Br J Dermatol. 2019;181:544-53. https://doi.org/10.1111/bjd.17632.

68. Heppt MV, Steeb T, Ruzicka T, et al. Cryosurgery combined with topical interventions for actinic keratosis: a systematic review and meta-analysis. Br J Dermatol. 2019;180:740-8. https://doi. org/10.1111/bjd.17435.

69. Kaufmann R, Spelman L, Weightman W, et al. Multicentre intraindividual randomized trial of topical methyl aminolaevulinate-photodynamic therapy vs. cryotherapy for multiple actinic keratoses on the extremities. Br J Dermatol. 2008;158:994-9. https://doi.org/10.1111/j.1365-2133.2008.08488.x.

70. Simon JC, Dominicus R, Karl L, et al. A prospective randomized exploratory study comparing the efficacy of once-daily topical $0.5 \% 5$-fluorouracil in combination with $10.0 \%$ salicylic acid (5-FU/SA) vs. cryosurgery for the treatment of hyperkeratotic actinic keratosis. J Eur Acad Dermatol Venereol. 2015;29:881-9. https://doi.org/10.1111/jdv.12702.

71. Zane C, Facchinetti E, Rossi MT, et al. Cryotherapy is preferable to ablative $\mathrm{CO} 2$ laser for the treatment of isolated actinic keratoses of the face and scalp: a randomized clinical trial. Br J Dermatol. 2014;170:1114-21. https://doi.org/10.1111/bjd.12847.

72. Krawtchenko N, Roewert-Huber J, Ulrich M, et al. A randomised study of topical $5 \%$ imiquimod vs. topical 5-fluorouracil vs. cryosurgery in immunocompetent patients with actinic keratoses: a comparison of clinical and histological outcomes including 1-year follow-up. Br J Dermatol. 2007;157:34-40. https://doi. org/10.1111/j.1365-2133.2007.08271.x.

73. Berman B, Shabbir AQ, MacNeil T, et al. Variables in cryosurgery technique associated with clearance of actinic keratosis. 
Dermatol Surg. 2017;43:424-30. https://doi.org/10.1097/DSS. 0000000000000989.

74. Thai KE, Fergin P, Freeman M, et al. A prospective study of the use of cryosurgery for the treatment of actinic keratoses. Int $\mathbf{J}$ Dermatol. 2004;43:687-92. https://doi.org/10.1111/j.1365-4632. 2004.02056.x.

75. De Berker D, McGregor JM, Mohd Mustapa MF, et al. British Association of Dermatologists' guidelines for the care of patients with actinic keratosis 2017. Br J Dermatol. 2017;176:20-43. https://doi.org/10.1111/bjd.15107.

76. Chiarello SE. Cryopeeling (extensive cryosurgery) for treatment of actinic keratoses: an update and comparison. Dermatol Surg. 2000;26:728-32. https://doi.org/10.1046/j.1524-4725.2000. 99197.x.

77. Taub AF, Garretson CB. A randomized, blinded, bilateral intraindividual, vehicle-controlled trial of the use of photodynamic therapy with 5-aminolevulinic acid and blue light for the treatment of actinic keratoses of the upper extremities. J Drugs Dermatol. 2011;10:1049-56.

78. Tschen EH, Wong DS, Pariser DM, et al. Photodynamic therapy using aminolaevulinic acid for patients with nonhyperkeratotic actinic keratoses of the face and scalp: phase IV multicentre clinical trial with 12-month follow up. Br J Dermatol. 2006;155:1262-9. https://doi.org/10.1111/j.1365-2133.2006. 07520.x.

79. Wiegell SR, Haedersdal M, Eriksen P, et al. Photodynamic therapy of actinic keratoses with $8 \%$ and $16 \%$ methyl aminolaevulinate and home-based daylight exposure: a double-blinded randomized clinical trial. Br J Dermatol. 2009;160:1308-14. https://doi.org/10.1111/j.1365-2133.2009.09119.x.

80. Wiegell SR, Fabricius S, Heydenreich J, et al. Weather conditions and daylight-mediated photodynamic therapy: protoporphyrin IX-weighted daylight doses measured in six geographical locations. Br J Dermatol. 2013;168:186-91. https://doi.org/10.1111/j. 1365-2133.2012.11200.x.

81. Lerche CM, Heerfordt IM, Heydenreich J, Wulf HC. Alternatives to outdoor daylight illumination for photodynamic therapyuse of greenhouses and artificial light sources. Int J Mol Sci. 2016;17(3):309. https://doi.org/10.3390/ijms17030309.

82. O'Mahoney P, Haigh N, Wood K, et al. A novel light source with tuneable uniformity of light distribution for artificial daylight photodynamic therapy. Photodiagn Photodyn Ther. 2018;23:14450. https://doi.org/10.1016/j.pdpdt.2018.06.013.

83. Dattola A, Gutiérrez Garcìa-Rodrigo C, Tambone S, et al. 5-Aminolaevulinic acid patch photodynamic therapy for the treatment of actinic keratoses: preliminary results from an Italian study in the real-life setting. G Ital Dermatol Venereol. 2020;155:636-41. https://doi.org/10.23736/S0392-0488.20.06598-0.

84. Mordon S, Vignion-Dewalle AS, Abi-Rached H, et al. The conventional protocol vs a protocol including illumination with a fabric-based biophotonic device (the Phosistos protocol) in photodynamic therapy for actinic keratosis: a randomized, controlled, noninferiority clinical study. Br J Dermatol. 2020;182:76-84. https://doi.org/10.1111/bjd.18048.

85. Algorri JF, Ochoa M, Roldán-Varona P, Rodríguez-Cobo L, López-Higuera JM, et al. Photodynamic therapy: a compendium of latest reviews. Cancers (Basel). 2021;13:4447. https://doi.org/ 10.3390/cancers 13174447.

86. Lawrence N, Cox SE, Cockerell CJ, et al. A comparison of the efficacy and safety of Jessner's solution and 35\% trichloroacetic acid vs $5 \%$ fluorouracil in the treatment of widespread facial actinic keratoses. Arch Dermatol. 1995;131:176-81.

87. Steeb T, Koch EAT, Wessely A, et al. Chemical peelings for the treatment of actinic keratosis: a systematic review and metaanalysis. J Eur Acad Dermatol Venereol. 2021;35:641-9. https:// doi.org/10.1111/jdv.16844.
88. Tai F, Shah M, Pon K, et al. Laser resurfacing monotherapy for the treatment of actinic keratosis. J Cutan Med Surg. 2021;2021:12034754211027516. https://doi.org/10.1177/12034 754211027515.

89. Lai M, Pampena R, Cornacchia L, et al. Treatments of actinic cheilitis: a systematic review of the literature. J Am Acad Dermatol. 2020;83:876-87. https://doi.org/10.1016/j.jaad.2019.07. 106.

90. Fleming P, Zhou S, Bobotsis R, et al. Comparison of the treatment guidelines for actinic keratosis: a critical appraisal and review. J Cutan Med Surg. 2017;21:408-17. https://doi.org/10. 1177/1203475417708166.

91. Heppt MV, Steeb T, Leiter U, et al. Efficacy of photodynamic therapy combined with topical interventions for the treatment of actinic keratosis: a meta-analysis. J Eur Acad Dermatol Venereol. 2019;33:863-73. https://doi.org/10.1111/jdv.15459.

92. Steeb T, Wessely A, Leiter U, et al. The more the better? An appraisal of combination therapies for actinic keratosis. J Eur Acad Dermatol Venereol. 2020;34:727-32. https://doi.org/10. $1111 / j d v .15998$.

93. Jambusaria-Pahlajani A, Ortman S, Schmults CD, et al. Sequential curettage, 5 fluorouracil, and photodynamic therapy for field cancerization of the scalp and face in solid organ transplant recipients. Dermatol Surg. 2016;42:S66-72. https://doi.org/10. 1097/DSS.0000000000000589.

94. Gholam P, Fink C, Bosselmann I, et al. Retrospective analysis evaluating the effect of a keratolytic and physical pretreatment with salicylic acid, urea and curettage on the efficacy and safety of photodynamic therapy of actinic keratoses with methylaminolaevulinate. J Eur Acad Dermatol Venereol. 2016;30:619-23. https://doi.org/10.1111/jdv.13449.

95. Lambert SR, Mladkova N, Gulati A, et al. Key differences identified between actinic keratosis and cutaneous squamous cell carcinoma by transcriptome profiling. Br J Cancer. 2014;110:520-9. https://doi.org/10.1038/bjc.2013.760.

96. Cramer P, Stockfleth E. Actinic keratosis: where do we stand and where is the future going to take us? Expert Opin Emerg Drugs. 2020;25:49-58. https://doi.org/10.1080/14728214.2020.17308 10.

97. Szeimies RM, Bichel J, Ortonne JP, et al. A phase II dose-ranging study of topical resiquimod to treat actinic keratosis. Br J Dermatol. 2008;159:205-10. https://doi.org/10.1111/j.1365-2133. 2008.08615.x.

98. Stockfleth E, Hofbauer GFL, Reinhold U, et al. Topical resiquimod dosing regimens in patients with multiple actinic keratoses: a multicentre, partly placebo-controlled, double-blind clinical trial. Br J Dermatol. 2019;180:297-305. https://doi.org/10.1111/ bjd.17124.

99. Rajaratnam R. Resiquimod for actinic keratosis: is this a new treatment option? Br J Dermatol. 2019;180:254-5. https://doi. org/10.1111/bjd.17436.

100. Safety and Efficacy Study of AM001 cream in the treatment of actinic keratosis [Internet]. 2019. https://clinicaltrials.gov/ct2/ show/NCT03210740. Accessed 31 Dec 2019.

101. Pflugfelder A, Andonov E, Weide B, et al. Lack of activity of betulin-based Oleogel-S10 in the treatment of actinic keratoses: a randomized, multicentre, placebo-controlled double-blind phase II trial. Br J Dermatol. 2015;172:926-32. https://doi.org/10.1111/ bjd.13342.

102. Cerio R. The importance of patient-centred care to overcome barriers in the management of actinic keratosis. J Eur Acad Dermatol Venereol. 2017;31(Suppl 2):17-20. https://doi.org/10.1111/ jdv. 14091.

103. Thorell K, Midlöv P, Fastbom J, Halling A. Use of potentially inappropriate medication and polypharmacy in older adults: a 
repeated cross-sectional study. BMC Geriatr. 2020;20(1):73. https://doi.org/10.1186/s12877-020-1476-5.

104. Neri L, Peris K, Longo C, Actinic Keratosis-TReatment Adherence INitiative (AK-TRAIN) study group, et al. Physician-patient communication and patient-reported outcomes in the actinic keratosis treatment adherence initiative (AK-TRAIN): a multicenter, prospective, real-life study of treatment satisfaction, quality of life and adherence to topical field-directed therapy for the treatment of actinic keratosis in Italy. J Eur Acad Dermatol Venereol. 2019;33(1):93-107. https://doi.org/10.1111/jdv.15142. 